\title{
Food Allergy in Children with Asthma: Prevalence and Correlation with Clinical Severity of Respiratory Disease
}

\author{
E. Calamelli, G. Ricci*, V. Dell’Omo, B. Bendandi and M. Masi
}

Department of Paediatrics, S. Orsola-Malpighi Hospital, University of Bologna, Italy

\begin{abstract}
Epidemiological evidence suggests that there is a link between asthma and food allergy. The aim of this study was to estimate the prevalence of food allergy in asthmatic children and to evaluate a possible impact of food allergy on asthma severity. The study enrolled 103 asthmatic children (mean age: 11 years). Skin prick-test, dosage of specific IgE to a standardized panel of inhalant and food allergens and spirometric evaluation was made for each patient. Twenty-four (23\%) patients presented food allergy, $75(77 \%)$ were sensitized to at least one food. A lower rate of children with controlled symptoms was found in children with food allergy and a higher rate of persistent asthma was found in children sensitized to at least 4 foods. In conclusion, food allergy/sensitization should always be investigated in asthmatic children for its association with increasing severity (only in food sensitized patients) and reduced control of asthmatic symptoms.
\end{abstract}

Keywords: Asthma, food allergy, oral allergy syndrome.

\section{INTRODUCTION}

Allergic diseases have increased over the last years, as many epidemiological studies confirm. Food allergy is often the first manifestation of allergy in childhood: it occurs in $6 \%$ to $8 \%$ of the paediatric population younger than 3 years and $2 \%$ to $3 \%$ of the general paediatric population [1]. In young children, foods responsible for the vast majority of reactions are milk, egg, peanut, tree nuts, fish and shellfish.

Allergic reactions after ingestion of raw vegetables and fruits are also common, and may provoke both mild (such as 'oral allergy syndrome') than more severe reactions.

Early childhood allergies to milk, egg, soy and wheat usually resolve by school age ( $80 \%$ of cases); peanut, tree nut and seafood allergy are usually considered permanent [2]. Epidemiological evidence suggests that there is a link between asthma and food allergy. The statistical association between these two allergic diseases may be due to their common atopic basis or may reflect a close inter-relationship in their pathogenesis [3].

Asthma is considered the most frequent pulmonary disease in infancy [4] and is a significant cause of morbidity and mortality in the paediatric population, especially in the inner-city [5].

Although many studies have shown an association between food allergy and respiratory allergy (e.g. oral allergy syndrome in pollinosis), the true prevalence of food allergy in the population with asthma is unknown. In 1988, Novembre et al. [6], found that out of 140 asthmatic children (range: 2-9 years), 48 (34\%) presented a referred history of food allergy, but this was confirmed by food challenges in only 16 cases (11.4\%). Another paper [7] investigated the prevalence of food allergy in 6672 schoolchildren aged 9-11

*Address correspondence to this author at the Department of Paediatrics, S. Orsola-Malpighi Hospital; University of Bologna, Italy;

E-mail: giampaolo.ricci@unibo.it years recruited from 108 schools randomly selected in six French cities: of the children with asthma and concomitant allergic rhinitis, $6.4 \%$ reported symptoms of food allergy and $4.5 \%$ were sensitized to food allergens; of the children with only asthma, $2.9 \%$ reported symptoms of food allergy and $3.2 \%$ were sensitized to food allergens. However, more recent studies estimated that $4 \%$ to $8 \%$ of children with asthma have coexistent food allergy $[8,9]$.

In recent years, some authors have focused on the possible link between food allergy and asthma severity $[10,11]$.

Wang et al. [11] investigated the degree of food allergen sensitization in 504 sera from inner-city children with asthma (mean age: 6 years; range: 4-9) enrolled from emergency departments and clinics in inner-city areas in United States and evaluated the impact of food sensitization on asthma morbidity. In the group (45\% children) sensitized against at least one food allergen, the authors found a higher rate of hospitalisation $(p<0.01)$ and required more steroid medications $(\mathrm{p}=0.025)$ than non-sensitized individuals.

In a case-controlled study [10], food allergy was found to be a significant risk factor $(p=0.006)$ for life-threatening asthma: out of 54 asthmatic children (range: 1-16 years), the prevalence of food allergy was higher (10 cases; $52.6 \%)$ in 19 children ventilated for a life threatening asthma, than in controls with mild asthma (4 cases; $10.5 \%$ ).

This study was performed with the aim to estimate the real prevalence of food allergy and food allergen sensitization in asthmatic children and to evaluate a possible impact of food allergy on the severity and control of respiratory disease.

\section{MATERIALS AND METHODOLOGY}

\section{Subjects}

The study involved 103 children (69 males and 34 females) with a mean age of 11 years, (range 7-19 years) referred to the Allergologic Center of the Pediatric Department 
of Bologna University. For inclusion all patients had to have a clinical history of inhalant allergen-induced asthma (with or without associated allergic rhinitis). Inhalant allergen sensitization was defined by skin prick test (Lofarma, Milan; Italy). Classification of severity of asthma (intermittent, mild persistent, moderate persistent, severe persistent) was evaluated according to criteria provided by GINA guidelines [12]. All patients were allowed to take medications (oral/topic antihistamines, nasal corticosteroids, inhaled corticosteroids in association or not with long-acting or short-acting $\beta 2$-agonists) according to grade of severity of asthma and rhinoconjunctivitis when associated (GINA and ARIA guidelines [12,13]).

This research was conducted in accordance with the principles of the Declaration of Helsinki; informed consent was obtained by children and their parents.

\section{Skin Prick-Test}

At enrolment all patients were given the skin-prick test (SPT) with a panel of allergenic extracts (Lofarma, Milan; Italy): timothy grass pollen, birch tree pollen (Betula verucosa), hazel tree pollen (Corylus avellana), olive-tree (Olea), wall pellitory (Parietaria), Alternaria, cat, dog, dust mite $(D$. pteronyssinus, D. farinae), egg, milk, soy, wheat, fish, peanut, hazelnut, apple and kiwi.

A SPT result was considered positive when a wheal of at least $3 \mathrm{~mm}$ greater than the negative control was recorded 15 min after the application of the test.

\section{In Vitro Test}

Specific IgE (sIgE) were detected by the means of the CAP system (UniCAP 1000, Phadia, Sweden).

The sera of six patients were not available at enrolment: only 97/103 sera were analyzed.

All sera were performed with a panel of allergenic extracts: timothy grass pollen (Phleum pratense and Cynodon dactylon), birch tree pollen (Betula verucosa), hazel tree pollen (Corylus avellana), olive-tree (Olea), wall pellitory (Parietaria), Alternaria, cat, dog, dust mite (D. pteronyssinus, $D$. farinae), egg, milk, soy, wheat, fish, peanut, hazelnut, apple and kiwi.

Values of specific IgE greater than $0.35 \mathrm{kU} / \mathrm{L}$ were considered positive.

\section{Follow-Up of Respiratory Disease}

All patients underwent at least three spirometric tests (ZAN100 Rhino FLOWHANDY II; Zan Ferraris; Germany): at enrolment $\left(\mathrm{t}_{0}\right)$ and at six $\left(\mathrm{t}_{1}\right)$ and 12 months $\left(\mathrm{t}_{2}\right)$ after enrolment. Lung volumes (FVC, FEV 1 , FEV $\mathrm{FEV}_{1} / \mathrm{FV}$, PEF 25$75)$ were recorded before and 15 minutes after the inhalation of a dose of short-acting $\beta 2$-agonist (salbutamol: $200 \mu \mathrm{g}$ ).

Evaluation of asthma control was performed at $t_{0}, t_{1}$ and $\mathrm{t}_{2}$ : asthma was defined as controlled, partially controlled and uncontrolled $[12,14]$.

\section{Food Allergy Diagnosis} lergy.

All patients were evaluated for the presence of food al-

All subjects were questioned about symptoms of food allergy and age of onset of symptoms.
Food allergy was defined as certain in patients with positive open food challenge and a convincing clinical history of acute reactions with a documented level of specific $\mathrm{IgE}$ against the food considered $[15,16]$.

Food allergy was defined as probable in patients who had not performed oral challenge, but reported a clinical history suggestive for food allergy and a level of specific IgE with positive predictive value (PPV) $>95 \%$ for the food considered, according to PPV values indicated by Sampson [17].

\section{Statistical Methods}

Data were stored by means of customized databases. Statistical analyses were carried out by means of the Statistical Package for Social Science (SPSS/PC; SPSS Inc., Chicago, IL, USA). The Chi-square test and the Student $t$-test were applied where appropriate. In particular, proportions were compared by Chi-square test; geometric mean levels of specific and total $\mathrm{IgE}$ were compared by Student $t$-test.

Probability $(p)$ values of less than 0.05 were considered significant.

\section{RESULTS}

At enrolment 59 patients (58\%) had intermittent asthma, $33(32 \%)$ mild persistent asthma, $10(10 \%)$ moderate asthma and only one patient severe asthma.

During the 1-year follow-up, 23 patients (22\%) presented a total control of asthma symptoms, $71(69 \%)$ partly control and $9(9 \%)$ no control. Mean age of onset of asthmatic symptoms was 7 years.

The prevalence of food allergy, allergic rhinitis, atopic eczema and age of onset of clinical manifestations are shown in Table 1. Eighty-seven (84\%) patients had grass pollen allergy, $36(35 \%)$ house dust mite allergy, $11(11 \%)$ cat dander allergy, 3 (3\%) birch pollen allergy, $2(2 \%)$ dog dander allergy, $2(2 \%)$ hazel pollen allergy. Twenty-three $(22 \%)$ patients were allergic to both grass pollen and house dust mite.

Of the 97 sera available, $89(92 \%)$ were positive to grass pollen and $61(63 \%)$ to both birch and grass pollen. All patients sensitized to birch pollen were also sensitized to grass pollen.

Table 1. Prevalence of Asthma, Allergic Rhinitis, Food Allergy, Atopic Eczema and Respective Diseases and Age of Onset of Clinical Manifestations in 103 Children with Allergic Asthma

\begin{tabular}{|l|c|c|c|}
\hline \multicolumn{1}{|c|}{ Disease } & Mean Age of Onset & Lifetime N (\%) & Past N (\%) \\
\hline \hline Asthma & 7 years & $103(100)$ & - \\
\hline Allergic Rhinitis & 6 years & $70(68)$ & - \\
\hline Food Allergy & 2 years & $24(23)$ & $9(9)$ \\
\hline Atopic Eczema & 8 months & $16(15)$ & $29(28)$ \\
\hline
\end{tabular}

\section{Food Allergen Sensitization}

Seventy-five $(77 \%)$ subjects were sensitized against at least one food allergen.

The prevalence and level of sensitization against each food allergen tested is shown in Table 2. 
Table 2. Prevalence and Level of Sensitization Against Food Allergen Tested in Sera of 97 Asthmatic Children

\begin{tabular}{|c|c|c|c|c|c|}
\hline Food & $\begin{array}{c}\text { Presence of Sensitiza- } \\
\text { tion n (\%) }\end{array}$ & $\begin{array}{c}\text { Presence of Patients with }>95 \% \\
\text { Positive Predictive Level* }\end{array}$ & $\begin{array}{c}\text { Geometric Mean } \\
\text { sIgE (kU/L) }\end{array}$ & Range of sIgE (kU/L) & $\begin{array}{c}\text { Presence of Patients } \\
\text { with Food Allergy n }\end{array}$ \\
\hline \hline Egg & $29(30)$ & 5 & 1.4 & $0.39-36.3$ & 9 \\
\hline Milk & $27(28)$ & 1 & 1.7 & $0.38->100$ & 4 \\
\hline Fish & $11(11)$ & 1 & 1.4 & $0.36->100$ & 4 \\
\hline Peanut & $64(66)$ & 14 & 1.9 & $0.35-42.1$ & 14 \\
\hline Soy & $49(50)$ & 0 & 2.15 & $0.36-17.5$ & 0 \\
\hline Wheat & $65(67)$ & 0 & 2.4 & $0.3-31$ & 0 \\
\hline
\end{tabular}

*According to Sampson [17].

Most of the children were sensitized against plant foods, such as wheat ( 65 cases; $67 \%$ ), peanut (64 cases; $66 \%$ ) and soy (49 cases; $50 \%$ ). Less than half of the sera were positive to animal derived foods, such as egg (29 cases; $30 \%)$, milk (27 cases; $28 \%$ ) and fish (11 cases; $11 \%$ ). Fourteen patients presented a $>95 \%$ positive predictive level of specific $\operatorname{IgE}$ according to values determined by Sampson [17] against peanut. Of these subjects one had the food allergy confirmed in food challenge, one had never eaten peanuts due to the persistence of high values of specific IgE, and one had outgrown peanut allergy. Eleven children out of 14 with $>95 \%$ positive predictive level of specific $\operatorname{IgE}$ against peanuts were able to eat peanuts without any adverse reaction.

Specific IgE against milk and fish presented a wide range (even values $>100 \mathrm{kU} / \mathrm{L}$ ).

\section{Food Allergy and Correlated Symptoms}

Twenty-four children (23\%) had food allergy; in 21 cases diagnosis was confirmed in oral challenge. Mean age of onset of food allergy (for the first food) was about 2 years (mean value). Of the 24 children with food allergy, the most frequent foods responsible for clinical manifestations (also in association) are: egg (9 cases; 12\%), hazelnut (7 cases; $9 \%$ ), peanut and kiwi ( 6 cases; $8 \%$ ), milk, fish, tomato and apple (4 cases; 5\%), banana, water-melon, peach ( 3 cases; 4\%), walnuts, pepper, carrot, peas, beans, cherry and apricot in 2 cases (3\%), almonds, egg-plant, fennel, strawberry, melon, pineapple and orange one case (1\%). Two cases of reported anaphylactic shock had been induced by tree nut in one case and egg in the other. Clinical manifestations of food allergy were reported only by 21 subjects with food allergy confirmed by food challenge (Table 3). Thirteen subjects (62\%) presented oral allergy syndrome, 7 (33\%) respiratory symptoms (asthma or rhinitis), 7 (33\%) gastrointestinal symptoms (nausea, vomiting, diarrhoea) and 7 (33\%) symptoms limited to skin (eczema, urticaria). Only two children (10\%) reported anaphylactic shock. Food allergy induced asthma was seen only in 6 cases (29\%). Symptoms and respective eliciting food are summarized in Table 4. Oral allergy syndrome, rhinitis and urticaria were provoked by ingestion of vegetables or fruits. Seven children (33\%) out of 21 with food allergy confirmed by oral challenge presented oral allergy syndrome after ingestion of fruit or other raw vegetables. Four children $(19 \%)$ had oral allergy syndrome after ingestion of hazelnut. Gastrointestinal symptoms were associated with egg and fish.
Table 3. Clinical Manifestations of Food Allergy in 21 Asthmatic Children with Food Allergy Confirmed by Food Challenge

\begin{tabular}{|l|c|}
\hline \multicolumn{1}{|c|}{ Symptom } & Number of Subjects (\%) \\
\hline \hline Oral Allergy Syndrome & $13(62)$ \\
\hline $\begin{array}{l}\text { Gastrointestinal Symptoms } \\
\text { (nausea, vomiting, diarrhoea) }\end{array}$ & $7(33)$ \\
\hline Asthma (cough, wheeze) & $6(29)$ \\
\hline Urticaria & $4(19)$ \\
\hline Atopic Eczema & $3(14)$ \\
\hline Anaphylaxis & $2(5)$ \\
\hline Rhinitis & $1(10)$ \\
\hline
\end{tabular}

Table 4. Clinical Symptoms, According to Food Allergens, in 21 Asthmatic Children with Food Allergy Confirmed by Food Challenge

\begin{tabular}{|l|c|c|c|c|c|c|c|c|}
\hline \multicolumn{1}{|c|}{ Symptom } & M & E & F & P & L & H & N & V/F \\
\hline \hline Oral Allergy Syndrome & 1 & 1 & 1 & 1 & 1 & 4 & 1 & 7 \\
\hline $\begin{array}{l}\text { Gastrointestinal Symptoms } \\
\text { (nausea, vomiting, diarrhoea) }\end{array}$ & 0 & 4 & 2 & 0 & 0 & 1 & 0 & 0 \\
\hline Asthma (cough, wheeze) & 2 & 1 & 0 & 2 & 0 & 2 & 0 & 0 \\
\hline Urticaria & 1 & 0 & 0 & 0 & 1 & 1 & 1 & 2 \\
\hline Atopic Eczema & 2 & 2 & 0 & 1 & 0 & 1 & 0 & 0 \\
\hline Anaphylaxis & 0 & 1 & 0 & 0 & 0 & 1 & 1 & 0 \\
\hline Rhinitis & 0 & 0 & 0 & 1 & 0 & 1 & 0 & 0 \\
\hline
\end{tabular}

$\mathrm{M}=$ Milk; $\mathrm{E}=$ Egg; $\mathrm{F}=$ Fish; $\mathrm{P}=$ Peanut; $\mathrm{L}=$ Legumes; $\mathrm{H}=$ Hazelnut; $\mathrm{W}=$ Walnut; $\mathrm{V} / \mathrm{F}=$ Vegetables/Fruits.

\section{Food Allergy and Severity and Control of Respiratory Disease}

In Table 5 (Fig. 1) the relationship between food allergy and severity and control of respiratory disease is shown. There was no significant difference in the degree of severity of asthma among subjects affected or not by food allergy. In contrast, children without food allergy presented a higher rate of controlled asthma (25\%) than children with food allergy (only $12 \%$ ). 
Finally, a possible association between severity and/or control of asthmatic symptoms and presence of sensitization against food allergens (with or without symptoms of food allergy) was analysed. As shown in Table 6 (Fig. 2), subjects sensitized to at least four food allergens had a higher rate, though not significant ( 24 cases; $48 \%$ ), of persistent asthma (mild, moderate or severe) than children sensitized to no more than 3 food allergens ( 9 cases; $36 \%$ ), and than the children without any sensitization to food allergens ( 7 cases; $31 \%$ ). Moreover the children without food allergen sensitization or sensitized to up to 3 food allergens, presented a higher rate of controlled asthma $(23 \%$ in children without food allergen sensitisation and $36 \%$ in children sensitized to up to 3 food allergens) than children sensitized to at least 4 foods (only 16\%).

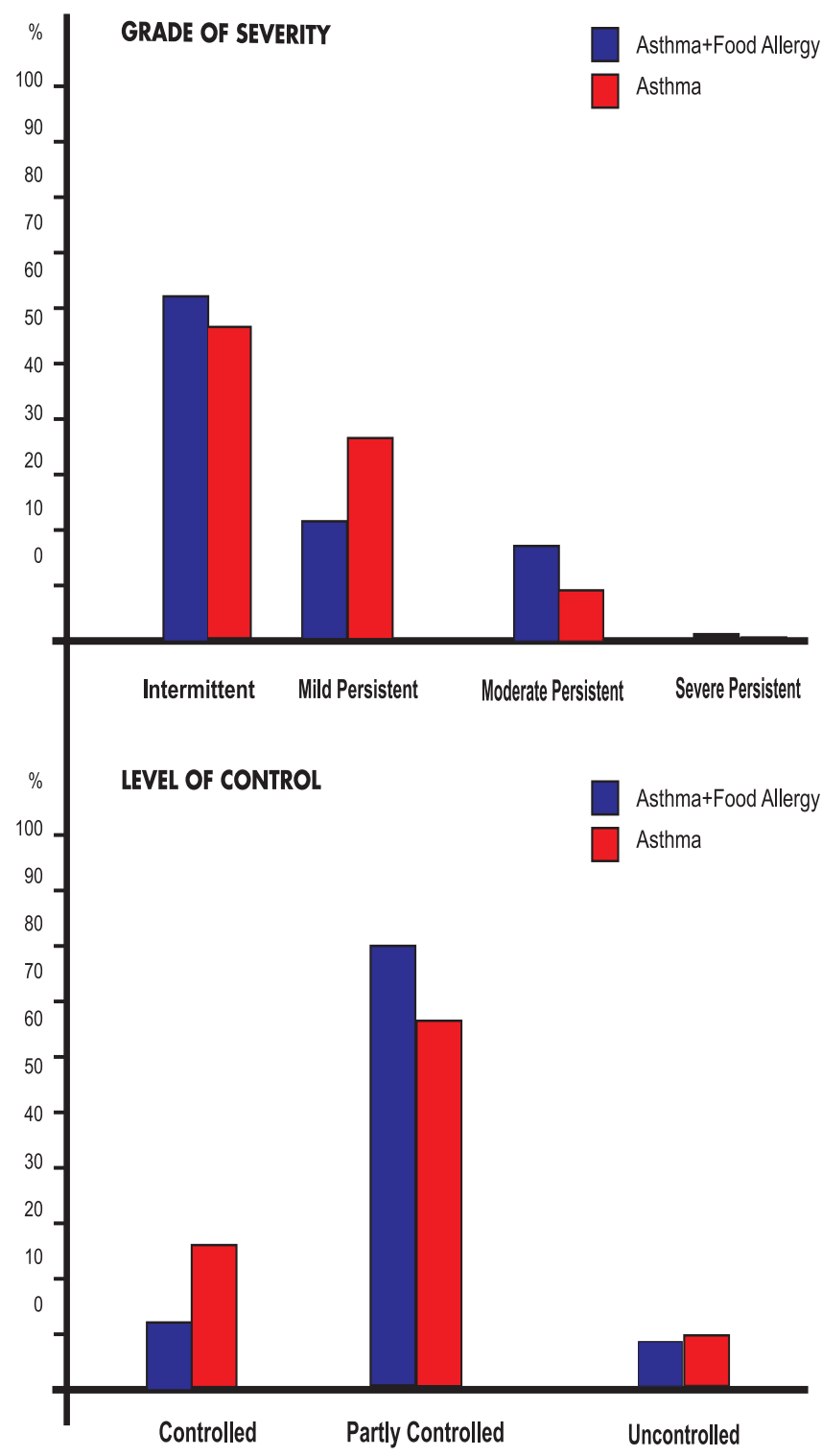

Fig. (1). Correlation between food allergy and severity and control of asthma in 103 asthmatic children.

\section{DISCUSSION}

The aim of this study was to determine the prevalence of food allergy in a population of asthmatic children and a pos- sible influence of food allergy on asthma severity and/or control.

Table 5. Correlation Between Food Allergy and Severity and Control of Asthma in 103 Asthmatic Children

\begin{tabular}{|c|c|c|c|}
\hline & $\begin{array}{c}>3 \text { Food } \\
\text { Allergens } \\
\mathbf{N}=50(\%)\end{array}$ & $\begin{array}{c}\leq 3 \text { Food } \\
\text { Allergens } \\
\mathbf{N}=25(\%)\end{array}$ & $\begin{array}{c}\text { No Food Allergen } \\
\text { Sensitization } \mathbf{N}=22(\%)\end{array}$ \\
\hline \multicolumn{4}{|c|}{ GRADE OF SEVERITY } \\
\hline Intermittent & $26(52)$ & $16(64)$ & $15(68)$ \\
\hline Persistent mild & $17(34)$ & $7(28)$ & $5(23)$ \\
\hline Persistent moderate & $6(12)$ & $2(8)$ & $2(9)$ \\
\hline Persistent severe & $1(2)$ & 0 & 0 \\
\hline \multicolumn{4}{|c|}{ LEVEL OF CONTROL } \\
\hline Controlled & $8(16)$ & $9(36)$ & $5(23)$ \\
\hline Partially controlled & $35(70)$ & $15(60)$ & $16(73)$ \\
\hline Uncontrolled & $7(14)$ & $1(4)$ & $1(4)$ \\
\hline
\end{tabular}

Table 6. Correlation Between Sensitization to Food Allergens and Severity and Control of Asthma in 97 Asthmatic Children

\begin{tabular}{|c|c|c|}
\hline & Asthma+Food Allergy N=24 (\%) & Asthma N=79 (\%) \\
\hline \multicolumn{3}{|c|}{ GRADE OF SEVERITY } \\
\hline Intermittent & $15(62)$ & $44(56)$ \\
\hline Persistent mild & $5(21)$ & $28(35)$ \\
\hline Persistent moderate & $4(17)$ & $6(8)$ \\
\hline Persistent severe & 0 & $1(1)$ \\
\hline \multicolumn{3}{|c|}{ LEVEL OF CONTROL } \\
\hline Controlled & $3(12)$ & $20(25)$ \\
\hline Partially controlled & $19(79)$ & $52(66)$ \\
\hline Uncontrolled & $2(8)$ & $7(9)$ \\
\hline
\end{tabular}

On the basis of the data acquired and analysed the following considerations can be made:

1. The prevalence of food allergy (defined as certain if confirmed in food challenge and possible in the case of history suggestive of food allergy with associated food specific IgE levels that had a $\geq 95 \%$ positive predictive value for food allergy according to levels identified by Sampson [17]) in asthmatic children aged 7-19 years (mean age: 7 years) was 23\% (24 cases);

2. The prevalence of food sensitization was $77 \%$ (97/103 sera available);

3. The main symptom of food allergy in a population of asthmatic children was oral allergy syndrome; 
4. No correlation was found between presence of food allergy and asthma severity, but only with the level of control of respiratory disease (Table 5; Fig. 1);

5. A correlation was found between food sensitization and grade of severity and control of asthma (Table 6; Fig. 2).

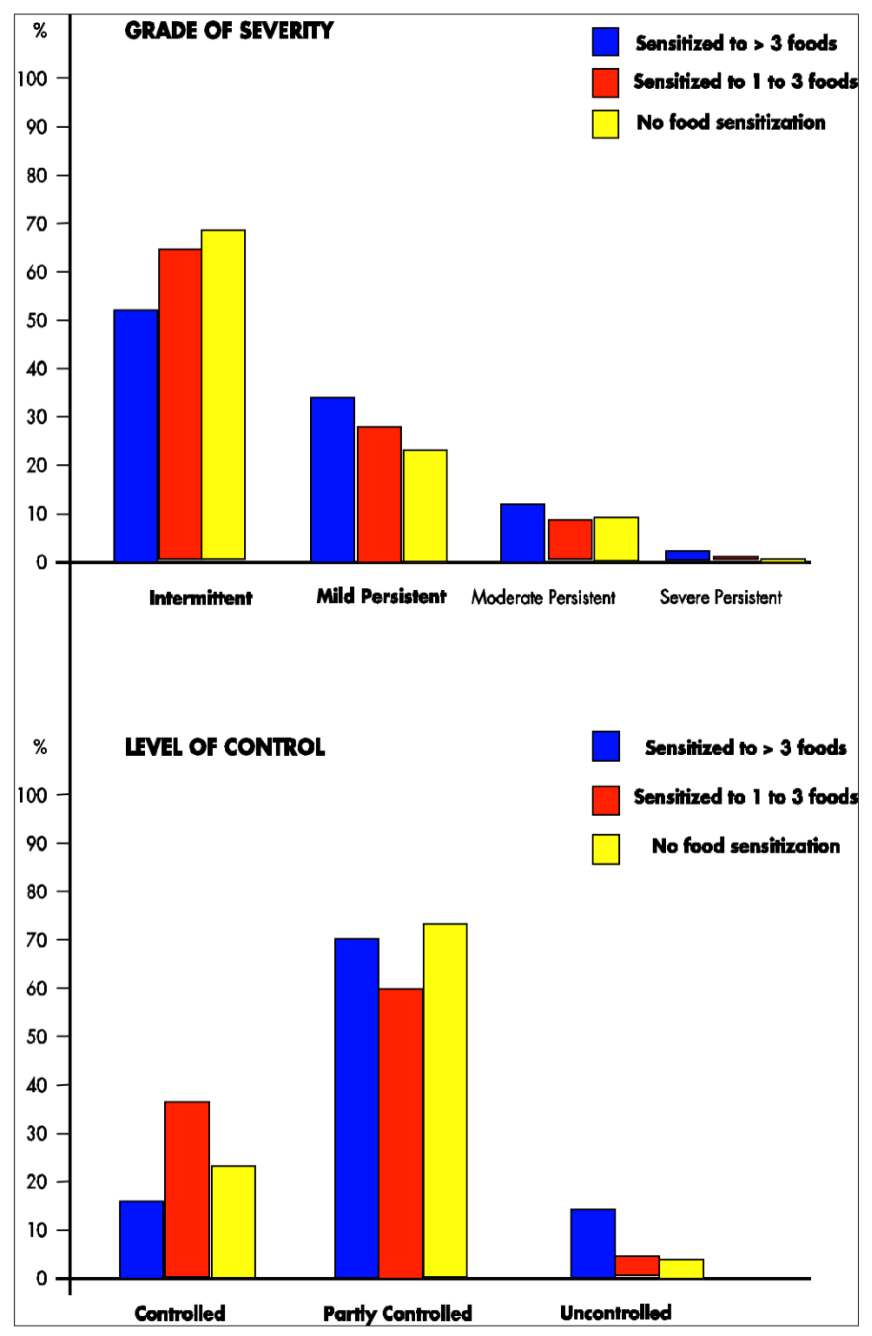

Fig. (2). Correlation between sensitization to food allergens and severity and control of asthma in 97 asthmatic children.

This study confirms the presence a higher prevalence of food allergy in asthmatic children $(23 \%)$ than the general paediatric population (2-3\%) Previous papers confirm that food allergy is highly prevalent among asthmatic patients, even though some studies show discordant data. The study by Novembre [6] (1988) shows a prevalence of food allergy in asthmatic children aged 2-8 years of 34\%. The present study included subjects aged 7-19 years: in part of them, most food allergies, in particular to egg or milk, were outgrown by the age of 5 years. Other papers show a higher prevalence of food allergy in asthmatic children. Rancé [4] estimated a prevalence of food allergy in asthmatic children of $78 \%$ on the basis of history reported by parents of the children without confirmation of food challenge: the real prevalence of food allergy was not determined.

In the present study egg, hazelnut and peanut were the three most frequent foods inducing food allergy. In contrast with a previous paper [4], milk allergy was not included in the three most frequent foods: this study included older children, who had probably already outgrown their milk allergy. The most common symptom found in 24 children with food allergy was oral allergy syndrome after the ingestion of raw plant-derived food $(13 / 24 ; 62 \%)$. Of the 13 children with oral allergy syndrome, 12 suffered from pollinosis: the prevalence of pollen-related food allergy in pollinosis children $(92 / 103)$ was about $13 \%$. Previous studies confirm this data. Cudowska [18] showed that out of 14 pollinosic children (aged 4-17 years old) suffering from food allergy, 3 $(21 \%)$ had oral allergy syndrome. As reported in previous papers, the prevalence of oral allergy syndrome in the adult population is higher than in children and is estimated at about $50-70 \%$ [19-22]. This difference can be explained by the association between pollen allergy duration and oral allergy syndrome, as the study by Asero et al. confirms [23]: the patients included in the present study were too young to present a higher prevalence of oral allergy syndrome. In contrast, food-induced asthma was not a common symptom in asthmatic children with food allergy: of 24 children with food allergy only 6 (29\%) reported wheezing after food ingestion.

A higher rate of children with controlled symptoms was found in children without food allergy, compared with children with food allergy ( $25 \%$ vs $12 \%)$, but no association was found with the grade of asthma severity. The study by Roberts et al. [10] had shown that out of children aged 1 to 16 years ventilated for life-threatening asthma, 10 (53\%) also suffered from food allergy and out of 38 children suffering from mild asthma enrolled as controls, 4 (11\%) suffered from food allergy: out of the total of 57 children enrolled, 14 $(25 \%)$ were affected by food allergy. This rate is similar to the rate found in the present study: this data seems to suggest that even if food allergy has a higher prevalence in asthmatic population, a correlation with severity can be found only by comparing mild cases with cases suffering from severe, life threatening asthma. In the present study too few patients suffered from severe asthma: more than half $(58 \%)$ of the children recruited suffered from intermittent asthma and only $11 \%$ from moderate or severe asthma.

Moreover, a higher rate of children with persistent asthma and uncontrolled symptoms was found in those sensitized to at least 4 foods. Among subjects sensitized to at least 4 food allergens, 24 (48\%) were affected by persistent asthma; among subjects sensitized to 1 to 3 foods, $9(36 \%)$ were affected by persistent asthma; only 7 (31\%) children without sensitization to any food had persistent asthma. Of the children sensitized to at least 4 allergens, 7 presented uncontrolled symptoms, compared with one child sensitized to 1 to 3 food allergens and to one nonsensitized child. Also Roberts [10] found an association between sensitization to food allergens and life-threatening asthma. Of 19 patients ventilated for life-threatening asthma, 10 (53\%) were sensitized to at least one food allergen and $8(42 \%)$ to 4 or more allergens (inhalant or food allergens). Of 38 controls with mild asthma, 5 (13\%) were sensitized to at least one food and $6(15 \%)$ were sensitized to 4 or more allergens (food or aeroallergens). Therefore Roberts indicated the presence of polysensitization in particular food sensitization as a risk factor for life threatening asthma. Julie Wang et al. [11], in a study on 504 sera of asthmatic children aged 4 to 9 years, similarly found a significant association between food sensi- 
tization and asthma severity. Children sensitized to at least one food (milk, egg, fish, wheat, soy and peanut) presented a higher rate of hospitalization and required more steroid medications than nonsensitized patients. Julie Wang too had enrolled only children with asthma recruited from emergency departments and clinics in inner-city areas, who presented a more severe disease.

The rate of food allergen sensitization among the children enrolled in the present study was higher than in those recruited by Wang and Roberts (77\% versus $45 \%$ and $26 \%$ respectively) and most children were sensitized to wheat (65; $87 \%)$, peanut $(64 ; 85 \%)$ and soy $(49 ; 65 \%)$. These discordant data could be explained by considering that the children in the present study were older and in more than $90 \%$ of cases suffered from pollinosis. In fact, while in the early age the sensitization to food allergens, in particular to egg and milk, can be considered a risk factor for development of respiratory allergic diseases, such as asthma or allergic rhinoconjunctivitis [24-32], in the following years of life the presence of pollinosis can determine the development of a 'pollenrelated food allergy', presenting oral allergy syndrome as a clinical manifestation [19-21, 33-38].

\section{CONCLUSIONS}

This paper represents the first study in recent years which has investigated the prevalence of both food allergy and food sensitization in a population of asthmatic children. No correlation was found between presence of food allergy and asthma severity, but only with the level of control of respiratory disease: children without food allergy presented a higher rate of controlled asthma $(25 \%)$ than children with food allergy (only 12\%).

Moreover, children sensitized to at least four food allergens had a higher rate, though not significant (24 cases; $48 \%$ ), of persistent asthma (mild, moderate or severe) than children sensitized to no more than 3 food allergens ( 9 cases; $36 \%$ ), and than the children without any sensitization to food allergens ( 7 cases; $31 \%$ ) and the children without food allergen sensitization or sensitized to up to 3 food allergens, presented a higher rate of controlled asthma $(23 \%$ in children without food allergen sensitization and $36 \%$ in children sensitized to up to 3 food allergens) than children sensitized to at least 4 foods (only 16\%).

Therefore, the presence of food allergy/sensitization should always be investigated in pollinosis children in particular if suffering from asthma. It may be interesting in a future study to widen the number of cases, to include a higher rate of subjects affected by severe asthma.

\section{REFERENCES}

[1] Bock S. Prospective appraisal of complaints of adverse reactions to foods in children during the first 3 years of life. Pediatrics 1987; 79: 683-8.

[2] Sicherer SH, Sampson HA. Food allergy. J Allergy Clin Immunol 2006; 117: S470-5.

[3] Roberts G, Lack G. Food allergy and asthma-what is the link? Paediatr Resp Rev 2003; 4: 205-12.

[4] Rancé F, Dutau G. Asthme lergies alimentaires: à propos de 163 observations pédiatriques. Arch Pédiatr 2002; 9: 402-7.

[5] Mannino DM, Homa DM, Pertowski CA, et al. Surveillance for asthma: United States, 1960-1995. MMWR CDC Surveill Summ 1998; 47: 1-27.
[6] Novembre E, De Martino M, Vierucci A. Foods and respiratory allergy. J Allergy Clin Immunol 1988; 81: 1059-65.

[7] Pénard-Morand C, Raherison C, Kopferschmitt C, et al. Prevalence of food allergy and its relationship to asthma and allergic rhinitis in schoolchildren. Allergy 2005; 60: 1165-71.

[8] Bousquet J, Neukirch F, Noyola A, Michel F-B. Prevalence of food allergy in asthma. Pediatr Allergy Immunol 1992; 3: 206-13.

[9] Sicherer SH, Sampson HA. The role of food allergy in childhood asthma. Immunol Allergy Clin North Am 1998; 18: 49-60.

[10] Roberts G, Patel N, Levi-Schaffer F, Habibi P, Lack G. Food allergy as a risk factor for life-threatening asthma in childhood: A case-controlled study. J Allergy Clin Immunol 2003; 112: 168-74

[11] Wang J, Visness CM, Sampson HA. Food allergen sensitisation in inner-city children with asthma. J Allergy Clin Immunol 2005; 115 : 1076-80

[12] GINA Report. Global strategy for asthma management and prevention. Revised 2006. Accessed 16 December 2006: Avaiable from: http://www.ginasthma.com/guidelineitem.asp??

[13] Bousquet J, VanCauwenberge P, Khaltaev N. Allergic rhinitis and its impact on asthma (ARIA) - executive summary. Allergy 2002; 57: 841-55.

[14] Li JT, Oppenheimer J, Bernstein L, Nicklas A. Attaining optimal asthma control: A practice parameter. J Allergy Clin Immunol 2005; 113: S3-S11.

[15] Dannaeus A, Inganaes M. A follow-up study of children with food allergy. Clinical course in relation to serum IgE and IgG-antibody levels to milk, egg and fish. Clin Allergy 1981; 1: 533-9.

[16] Sicherer SH, Noone SA, Koerner CB, et al. Hypoallergenicity and efficacy of an amino acid-based formula in children with cow's milk and multiple food hypersensitivities. J Pediatr 2001; 138: 68893.

[17] Sampson HA. Utility of food-specific IgE concentrations in predicting symptomatic food allergy. J Allergy Clin Immunol 2001; 107: 891-6.

[18] Cudowska B, Kaczmarski M. Diagnostic value of birch recombinant allergens (rBet v 1, profilin rBet $v 2$ ) in children with pollenrelated food allergy. Rocz Akad Med Byalymst 2004; 49: 111-5.

[19] Schimek EM, Zwolfer B, Briza P, et al. Gastrointestinal digestion of Bet $\mathrm{v}$ 1-homologous food allergens destroys their mediatorreleasing, but not $\mathrm{T}$ cell-activating, capacity. J Allergy Clin Immunol 2005; 116: 1327-33.

[20] Dreborg S, Foucard T. Allergy to apple, carrot and potato in children with birch pollen allergy. Allergy 1983; 38: 167-72.

[21] Wüthrich B, Stager J, Johansson SG. Celery allergy associated with birch and mugwort pollinosis. Allergy 1990; 45: 566-71.

[22] Ma S, Sicherer SH, Nowak-Wegrzryn A. A survey on the management of pollen-food allergy syndrome in allergy practice. $\mathrm{J}$ Allergy Clin Immunol 2003; 112: 784-8.

[23] Asero R, Massironi F, Velati C. Detection of prognostic factors for oral allergy syndrome in patients with birch pollen hypersensitivity. J Allergy Clin Immunol 1996; 97: 611-6.

[24] Wickman M. When allergies complicate allergies. Allergy 2005; 60: 14-18.

[25] Kulig M, Bergmann R, Tacke U, et al. Long-lasting sensitization to food during the first two years precedes allergic airways diseases. Pediatr Allergy Immunol 1998; 9: 61-7.

[26] Gustafsson D, Sjoberg O, Foucard T. Development of allergies and asthma in infants and young children with atopic dermatitis - a prospective follow up to 7 years of age. Thorax 2000; 55: 240-5

[27] Nickel R, Kulig M, Forster J, et al. Sensitization to hen's egg at the age of twelve months is predictive for allergic sensitization to common indoor and outdoor allergens at the age of three years. J Allergy Clin Immunol 1997; 99: 613-17

[28] Tariq SM, Matthews SM, Shakim EA, Arshad SH. Egg allergy in infancy predicts respiratory allergic disease by 4 years of age. Pediatr Allergy Immunol 2000; 11: 162-7.

[29] Illi S, von Mutius E, Lau S, et al. The pattern of atopic sensitisation is associated with the development of asthma in children. J Allergy Clin Immunol 2001; 108: 709-14.

[30] Sampaio G, Marino S, Prates S, Morais-Almeida M, Rosado-Pinto J. Transient vs persistent cow's milk allergy and development of other allergic diseases. Allergy 2004; 60: 411-12.

[31] Kurukulaaratchy RJ, Matthews S, Arshad SH. Defining childhood atopic phenotypes to investigate the association of atopic sensitisation with allergic disease. Allergy 2005; 60: 1280-6. 
[32] Ricci G, Patrizi A, Baldi E, et al. Long-term follow-up of atopic dermatitis: Retrospective analysis of related risk factors and association with concomitant allergic diseases. J Am Acad Dermatol 2006; 55: 765-71.

[33] Breiteneder H, Radauer C. A classification of plant food allergens. J Allergy Clin Immunol 2004; 113: 821-30.

[34] Mittag D, Vieths S, Vogel L, et al. Soybean allergy in patients allergic to birch pollen: clinical investigation and molecular characterization of allergens. J Allergy Clin Immunol 2004; 113: 148-54.

[35] Amlot PL, Kemeny DM, Zachary C, Lessof MH. Oral allergy syndrome (OAS): symptoms of IgE-mediated hypersensitivity to foods. Clin Allergy 1987; 17: 33-42.
[36] Ballmer-Weber BK, Vieths S, Luttkopf D, Heuschmann P, Wuthrich B. Celery allergy confirmed by double-blind, placebocontrolled food challenge: a clinical study in 32 subjects with a history of adverse reactions to celery root. J Allergy Clin Immunol 2000; $106: 373-8$.

[37] Kleine-Tebbe J, Wangorsch A, Vogel L, et al. Severe oral allergy syndrome and anaphylactic reactions caused by a Bet v 1-related PR-10 protein in soybean, SAM22. J Allergy Clin Immunol 2002; 110: 797-804.

[38] Ricci G, Righetti F, Menna G, et al. Relationship between Bet v 1 and Bet $\mathrm{v} 2$ specific IgE and Food allergy in children with grass pollen respiratory allergy. Mol Immunol 2005; 42: 1251-7.

(C) Calamelli et al.; Licensee Bentham Open.

This is an open access article distributed under the terms of the Creative Commons Attribution License (http://creativecommons.org/licenses/by/2.5/), which permits unrestrictive use, distribution, and reproduction in any medium, provided the original work is properly cited. 